\title{
Long-term prognosis after mitral annuloplasty for acquired mitral insufficiency Clinical evaluation
}

\author{
P. Penther ${ }^{1}$, J. P. Bourdarias, ${ }^{1}$ and J. Lenègre \\ From the Clinique Cardiologique, U.E.R. Necker, Boucicaut, 78 Rue de la Convention, \\ 75 Paris $X V^{e}$, France
}

Twenty-nine patients with isolated (I8) or predominant (II) mitral insufficiency were treated by mitral annuloplasty. This post-operative follow-up study, lasting from 3 to $5 \frac{1}{2}$ years (average 48 months), resulted in the following conclusions. The clinical, radiological, and electrocardiographic conditions usually followed a parallel course. Initial good results were maintained for up to 4 years in only I6 patients. Subsequent deterioration was related to progression to mitral stenosis (2 patients), recurrence of severe mitral insufficiency ( 13 patients), occurrence (5 patients) or recurrence ( 8 patients) of tricuspid insufficiency. Poor results were more often observed in the eldest patients, with conspicous pre-operative cardiac enlargement, atrial fibrillation, and long-standing cardiac failure. The indications for annuloplasty are reduced and apply primarily to mitral insufficiency without obvious cardiac enlargement, with normal sinus rhythm, and with shortstanding congestive cardiac failure.

Isolated or predominant mitral insufficiency, when poorly tolerated, may be corrected surgically either by prosthetic valve replacement or by mitral annuloplasty. Numerous studies dealing with long-term results of prosthetic valve replacement have been published, especially concerning the Starr-Edwards ball valve. But there are relatively few reports concerning the late results of mitral annuloplasty. The purpose of this study, based on a 3- to 5-year clinical follow-up, is to assess the long-term results of mitral annuloplasty in patients with acquired, pure, or predominant mitral insufficiency.

\section{Subjects}

Of 46 consecutive patients who underwent mitral annuloplasty for mitral insufficiency before $\mathbf{I}$ March 1966, 29 were still alive at the time of this report. Before operation all these patients were either in class III (7) or in Class IV (22) of the New York Heart Association functional classification (Fig. I). The first complaint dated back ro years on average (range from I to 17 years). All but one of the patients were either in intractable or relapsing congestive heart failure. The first signs of congestive cardiac failure appeared

Received 6 October 1969.

1 Chargé de Recherches, Institut National de la Santé et de la Recherche Médicale. on average $2 \frac{1}{2}$ years before the surgical repair (range from 4 months to ro years) and in most cases coincided with the onset of a durable atrial fibrillation.

In 18 patients ( 15 women and 3 men of an average age of, respectively, 31 and 43 years), mitral regurgitation was isolated. There was a documented history of rheumatic fever in 14. The mechanism responsible for the mitral regurgitation was variable; a mitral annulus dilatatation was frequently observed, either isolated (6) or associated with leaflet thickening (10); there was a leaflet perforation with ruptured chordae tendineae in I patient and an isolated rupture of the posterior leaflet chordae tendineae in another. Mitral incompetence was combined with a mild or moderate aortic insufficiency in 6 patients and with a tricuspid insufficiency in 7 . The surgical modification of the mitral valve has consisted of annuloplasty, performed according to Wooler (Wooler et al., 1962). In 2 patients a reconstructive operation was done on the tricuspid valve. Aortic insufficiency in 6 patients was neglected because it was mild or moderate.

In II patients (Io women, average age 36 years, with a range from 23 to 47 years, and I man aged 34), mitral insufficiency was associated with stenosis of a moderate degree (at the time of operation the mitral valve area was estimated as one and a half finger-breadth), which required a valvotomy before annuloplasty could be carried out. A history of rheumatic fever was found in all 
the patients. Mitral valve disease was combined in 4 patients with trivial aortic insufficiency which was not repaired, and in 4 patients with tricuspid insufficiency, which was corrected in I only (reconstructive operation).

\section{Methods}

Assessment of the long-term results of mitral annuloplasty was based on the follow-up of the 29 patients who have survived for more than 3 years after operation. In all patients the postoperative follow-up included a clinical, fluoroscopic, and electrocardiographic examination at least twice a year. A postero-anterior chest $x$-ray was available at least once a year. Phonocardiographic recordings were performed in most patients at regular intervals. Only one patient had cardiac catheterization (Seldinger's technique), and cine-angiocardiography 4 years after operation. Apical systolic murmurs were graded in intensity according to the usual scale ranging from $1 / 6$ to $6 / 6$. The cardiothoracic ratio was measured on the chest $x$-ray as the longest cardiac transverse diameter divided by the largest thoracic diameter between the inner rib margins. Criteria for right and left ventricular hypertrophy were those used in previous studies (Blondeau, Maurice, and Lenègre, 1962; Penther et al., I966). The comparison between the pre-operative and post-operative data was checked by the Student $t$ test using the method of paired comparisons.

\section{Results}

The over-all duration of the follow-up study averaged 48 months. The post-operative observation period exceeded 5 years in 3 patients, 4 years in ro patients, and 3 years in 17 patients. Residual mitral incompetence was assessed during the early post-operative period (between 4 and 6 weeks) by the demonstration of an apical systolic murmur and of a systolic expansion of the left atrium to fluoroscopy. But the clinical, radiographic, and electrocardiographic data, viewed as a whole, were first estimated at the beginning of the second year (average 16th month) and then more than 3 years following operation (range from 38 to 64 months).

Functional status The post-operative change in symptoms is described in Fig. $\mathbf{I}$. Functional improvement was initially good, since, at the beginning of the second year after operation, excellent or good results (class I or II) were noted in 2 I patients, and this improvement was maintained further. Indeed, more than 3 years after operation (average post-operative course of 48 months), I6 patients were still asymptomatic or could carry out their ordinary activities (class I and II). Later, however, of the 2 I patients who were much improved in the early post-

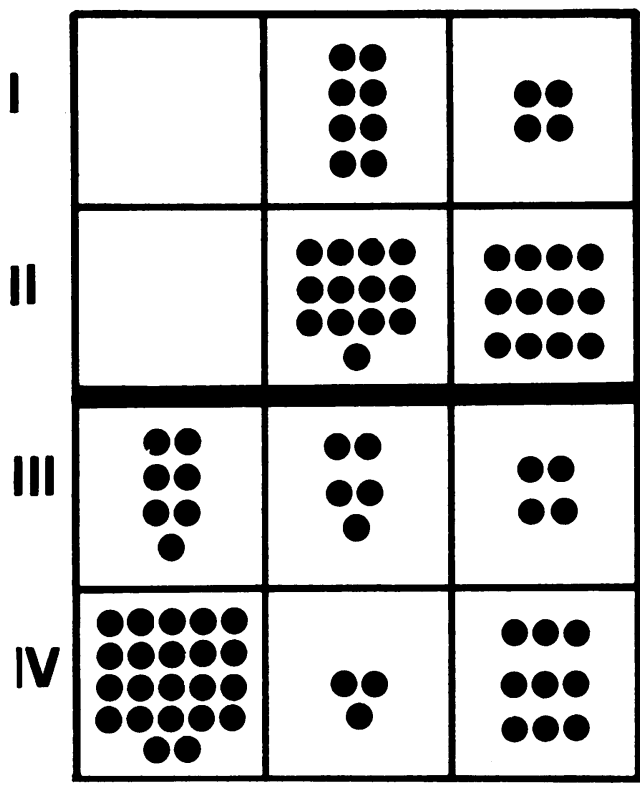

\section{pre-op $>1$ year $>3$ years}

FIG. I Functional status in 29 patients graded according to the New York Heart Association Classification. Left, before operation; centre, more than I year after operation (average 16 months); right, more than 3 years after operation (average 48 months).

operative phase, only I I remained so and in Io a gradual or sometimes sudden deterioration developed. Functional disability remained moderate in 4 of these ro patients who moved from class I to class II; in the other 6 patients, deterioration was important and resulted, between the third and fourth year after operation, in a functional status very close to that existing before operation.

Clinical and fluoroscopic criteria of mitral regurgitation In all but two patients, the mitral valve was judged to be competent by the surgeon at the end of operation. One month after operation on average, the apical systolic murmur had disappeared in 5 patients only; 24 patients still had a residual apical systolic murmur which was of mild intensity $(1 / 6)$ in 18 , and of moderate intensity $(2 / 6)$ in 6 (Fig. 2). An early diastolic third heart sound was audible in only 8 patients after operation as against 26 before operation. On fluoroscopic examination, with oesophageal opacification, an atrial systolic expansion, usually of a moderate degree, was seen in 17 patients. During the months and years after operation, the systolic murmurs on the whole tended to become gradually 
louder though they did not reach, with the exception of rare instances, their pre-operative level (Fig. 2). At the beginning of the second year after operation, a third heart sound could be detected in 13 patients; more than 3 years after operation this third heart sound was audible in 20 patients and was also shown on phonocardiographic recordings (Fig. 3). Simultaneously, as early as the second year, left atrial systolic expansion was seen in most cases, providing evidence of recurrence of mitral insufficiency. However, though relatively loud apical systolic murmurs were more frequently heard in patients with subsequent deterioration, intensity of the murmur by itself was not always closely related to the degree of the regurgitation assessed by other means.

Radiological data The cardiothoracic ratio changes tended, as shown in Fig. 4, to run parallel with the evolution of the functional status. The cardiothoracic ratio decreased significantly from $0.63 \pm 0.07$ before operation to $0.58 \pm 0.09$ at the beginning of the second year after operation $(p<0 \cdot 01)$. But during the next years the cardiothoracic ratio shifted in the opposite direction, and, as a consequence, about 48 months after operation it averaged $0.62 \pm 0.09$, a value similar to the pre-operative one.

Electrocardiographic data Abnormalities in the electrocardiogram (Table) were to some extent similar to those noted in the functional, physical, and radiological data (Fig. 5, 6, and 7). An attempt was made to restore sinus rhythm by electrical cardioversion in all the patients whose atrial fibrillation was of recent onset, and in whom atrial enlargement was relatively moderate. But more than 3 years after operation sinus rhythm was maintained in one-third of the patients only, yet all but one remained functionally

FIG. 2 Apical systolic murmur intensity: before annuloplasty (left) and, respectively, $I$ month, more than I year, and 3 years after annuloplasty.

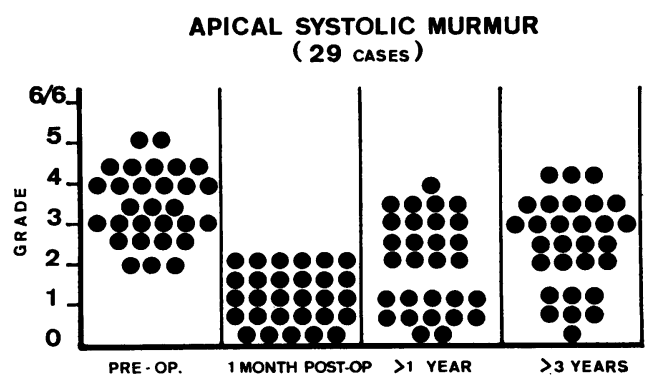

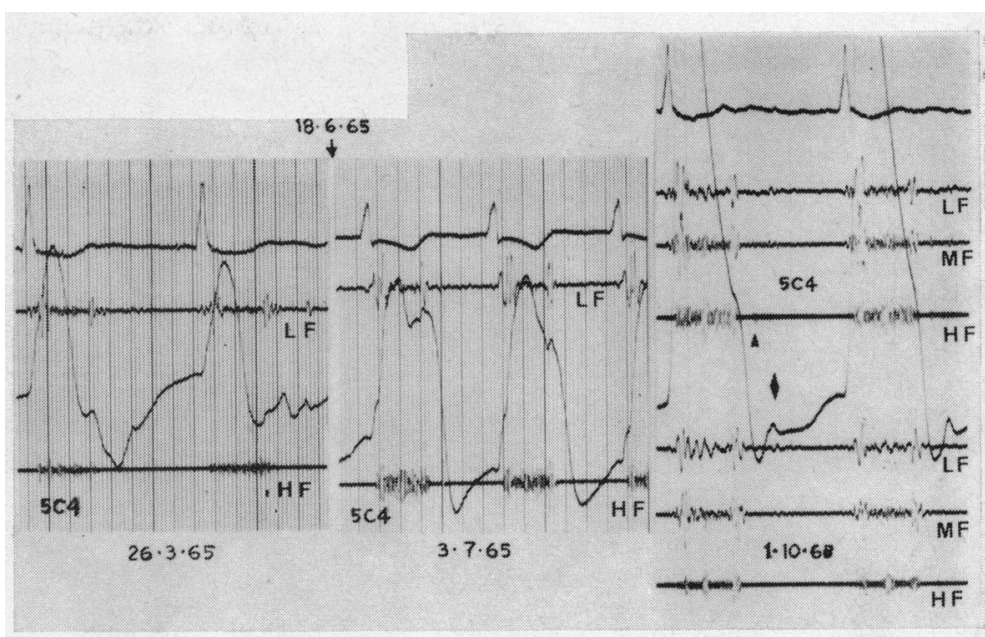

FIG. 3 Phonocardiogram from the mitral area (5 C4) and apex displacement curves in a woman with pure mitral insufficiency. Left, 3 months before operation; centre, I5 days; and right, 3 years after mitral annuloplasty. Note in the first post-operative tracing the disappearance of the rapid filling wave of the apex cardiogram but the persistence of a pansystolic murmur. Three years later, the rapid filling wave and a third heart sound $(\diamond)$ reappeared and a mid-diastolic murmur ( $\mathbf{\Lambda}$ ) was recorded, probably indicating mitral stenosis. $L F$, low frequency; $M F$, medium frequency; $H F$, high frequency.

much improved (class I and II). The frontal major QRS axis shifted from $+69^{\circ} \pm 37^{\circ}$ before operation to $+55^{\circ} \pm 38^{\circ}$ one year after operation $(\dot{p}<0.00 \mathrm{I})$, but in the third year it shifted again in the opposite direction, and averaged $+63^{\circ} \pm 39^{\circ}$, a value not significantly different from the pre-operative value. In very rare instances the $Q R S$ complexes returned to normal. The decrease in right ventricular hypertrophy occurred slowly and was not significant. The QRS voltages calculated from the praecordial leads (Sokolow-Lyon's index) decreased significantly during the early post-operative period from $36 \pm 9 \mathrm{~mm}$. to $27 \pm 8 \mathrm{~mm}$. ( $\mathrm{p}<0.00 \mathrm{r})$ and remained so during the following years $(29 \pm 9$ mm.; $p<0.01$ ). The sum SV2 $+\mathrm{RV}_{7}$ decreased from $33 \pm 12 \mathrm{~mm}$. to $28 \pm 7 \mathrm{~mm}$., one year after operation $(p<0.02)$ and again increased beyond 3 years to $3 I \pm 9 \mathrm{~mm}$. Non-ischaemic repolarization abnormalities were reduced on the whole but disappeared in rare instances and were the most persistent index of residual left ventricular hypertrophy.

Late complications Complications, or at least some of them, might be responsible for subsequent post-operative deterioration. Bac- 


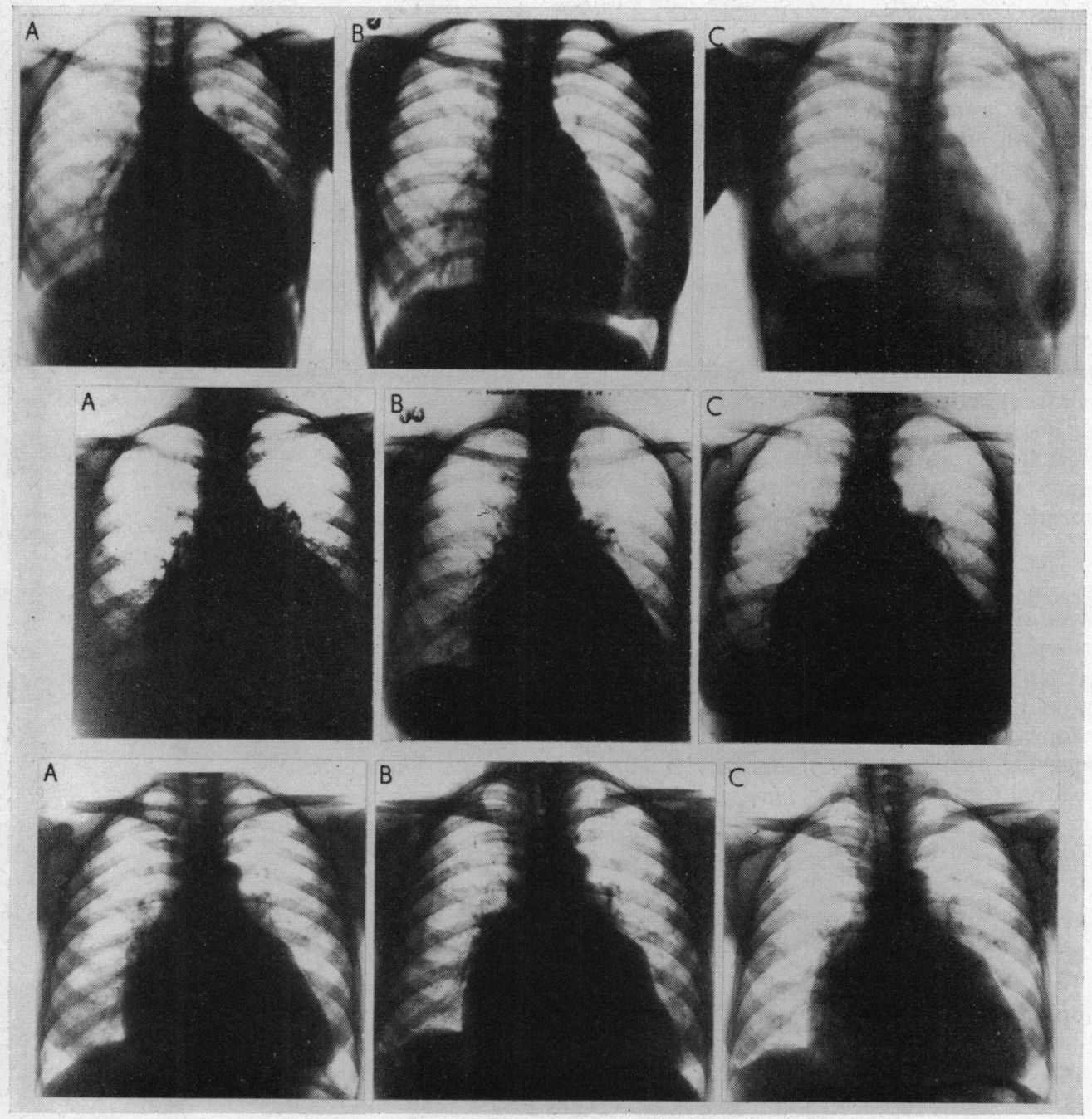

FIG. 4 Changes in heart size in three patients $(A)$ before operation, $(B)$ I year, and $(C)$ more than 3 years after operation. Top, pure mitral insufficiency of rheumatic origin (with mild aortic insufficiency) in a 13-year-old girl; functional status before operation, class IV; 20 months and 40 months after operation, class I. Middle, mixed mitral lesions, with predominant insufficiency and trivial stenosis in a 42-year-old woman; functional status: $(A)$ class $I V,(B)$ class $I I$, and $(C)$ class $I V$; associated tricuspid insuffciency. Bottom, pure mitral insufficiency of rheumatic origin (with mild aortic insufficiency) in a 48-year-old woman; functional status before operation, class $I V$; in $B$ (20 months after operation), and $C$ (45 months after operation), class $I V$ : valve replacement (Starr-Edwards prosthesis) was performed 48 months after annuloplasty.

terial endocarditis was never seen in this series. In spite of the high incidence of atrial fibrillation (noted in $58 \%$ and $64 \%$, respectively, $I$ and 3 years after operation) systemic embolisms were unusual, presumably because every patient in atrial fibrillation had anticoagulant treatment. In two patients only, a cerebral embolus occurred 4I and 60 months, respectively, after operation and resulted in trivial neurological lesions.
In most cases, on successive examinations residual mitral insufficiency was noticed and was sometimes increased. The mitral valve was still competent 46 months after operation in one patient only, as shown by the absence of any systolic murmur and of any detectable systolic expansion of the left atrium on fluoroscopy. In the other cases, residual mitral insufficiency was of variable degree, but tended to increase with time during the post- 
operative period. The incidence of a clinically moderate and steady mitral insufficiency decreased from about one-half (14 of the 29 patients) at the beginning of the second postoperative year to about one-third (Io patients) at the end of the fourth post-operative year. In 19 patients, the residual mitral insufficiency increased, and in 13 of them it resulted once more in a relapsing cardiac disabling invalidism. In the ro patients with a moderate and stable residual mitral insufficiency, the preoperative cardiothoracic ratio averaged $0.60 \pm$ 0.06 , and in only 2 of these patients was atrial fibrillation present. In the 19 patients who had a gradually increasing residual mitral insufficiency the average pre-operative cardiothoracic ratio was significantly higher $(0.65 \pm$ $0.06 \mathrm{p}<0.05)$; and 3 years after operation all these 19 patients were in atrial fibrillation. The mechanism of the residual mitral insufficiency was demonstrated at re-operation in 4 patients and confirmed by necropsy in 2 of them. Mitral annuloplasty, done several years before (range from 37 to 48 months), was still tight, but the part of the ring corresponding to the posterior leaflet insertion was overstretched, resulting in systolic regurgitation.

In over half the cases a mild diastolic rumbling murmur was audible. However, because of lack of haemodynamic data, the development of a significant mitral stenosis could be clinically assessed in 2 patients only. In the first, correction of a pure mitral insufficiency, combined with a slight dilatation of the mitral annulus, demanded such tightening of the mitral ring that the mitral area was reduced almost to the circumference of a forefinger. In the second case, both the commissures were fused along several millimetres but were not calcified, and a mitral valvotomy was performed before annuloplasty; 60 months later, an apical diastolic rumbling murmur was heard and for the first time valvar calcifications could be seen on fluoroscopy with a brilliance amplifier. In these two patients, no laboratory signs of inflammation could be seen.

A moderate pre-existing aortic insufficiency, which was noted in ro patients and not repaired surgically, did not change throughout the post-operative course and did not seem to influence the functional improvement. Tricuspid regurgitation was present in ro patients before operation. It was moderate in 6 patients and was not repaired, and severe in 4 , being corrected in 3 of them at the same time as annuloplasty was performed. In 2 patients only did moderate tricuspid regurgitation disappear during the year after mitral annuloplasty. One and a half
TABLE Electrocardiographic changes in 29 patients

\begin{tabular}{|c|c|c|c|}
\hline \multirow[t]{2}{*}{ Electrocardiographic findings } & \multirow{2}{*}{$\begin{array}{l}\text { Pre-operative } \\
\text { data }\end{array}$} & \multicolumn{2}{|c|}{ Post-operative data } \\
\hline & & $\begin{array}{l}>I \text { year }(16 \\
\text { months on } \\
\text { average })\end{array}$ & $\begin{array}{l}>3 \text { years }(48 \\
\text { months on } \\
\text { average })\end{array}$ \\
\hline \multicolumn{4}{|l|}{ Normal sinus rhythm } \\
\hline Frontal QRS axis $\left({ }^{\circ}\right)$ & $+69( \pm 37)$ & $+55( \pm 38)^{\star}$ & $+63( \pm 39) \mathrm{NS}$ \\
\hline Frontal $\mathrm{T}$ wave axis $\left({ }^{\circ}\right)$ & +23 & $+16 \mathrm{NS}$ & $+26 \mathrm{NS}$ \\
\hline QRS duration (lead DII) (sec.) & 0.099 & 0.092 & 0.096 \\
\hline $\begin{array}{l}\text { (lead V6) (sec.) } \\
\text { Sokolow-Lyon's index } \\
\left(S_{1}+R_{5}\right) \text { or }\left(S_{I}+R V 6\right)\end{array}$ & 0.057 & 0.052 & 0.053 \\
\hline $\begin{array}{l}(\mathrm{mm} .) \\
\left(\mathrm{SV}_{2}+\mathrm{RV}_{7}\right)(\mathrm{mm} .) \\
\text { Lewis' index }\end{array}$ & $\begin{array}{l}36( \pm 9) \\
33( \pm 12)\end{array}$ & $\begin{array}{l}27( \pm 8)^{\star} \\
28( \pm 7)^{t}\end{array}$ & $\begin{array}{l}29( \pm 9)^{\star} \\
31( \pm 9) \mathrm{NS}\end{array}$ \\
\hline $\begin{array}{l}\left(\mathrm{RI}_{\mathrm{I}}-\mathrm{R}_{3}\right)+\left(\mathrm{S}_{3}-\mathrm{S}_{\mathrm{I}}\right)(\mathrm{mm} .) \\
\mathrm{ST}-\mathrm{T} \text { abnormalities of non- } \\
\text { ischaemic origin (no. of } \\
\text { cases) }\end{array}$ & -1 & -2 & 26 \\
\hline
\end{tabular}

Standard deviation is given in parentheses.

$\star \mathrm{p}<0.001$.

$+\mathrm{p}<0.02$.

NS, not significant.

years after operation tricuspid regurgitation was still noted in 8 patients: clinically mild in 7 of them and intense in 1 , but 5 of these patients had poor functional results (Fig. 8). The incidence and degree of tricuspid regurgitation increased with time. In the fourth year after operation 13 patients had tricuspid insufficiency which remained moderate in 6 and did not influence functional improvement in 4 patients (Fig. 8), but was of high degree

FIG. 5 Electrocardiographic changes in the same patient as in Fig. 4 (top); note the persistence of normal sinus rhythm and the decreased $Q R S$ voltages in the praecordial leads (annuloplasty performed on 21 fanuary 1966).

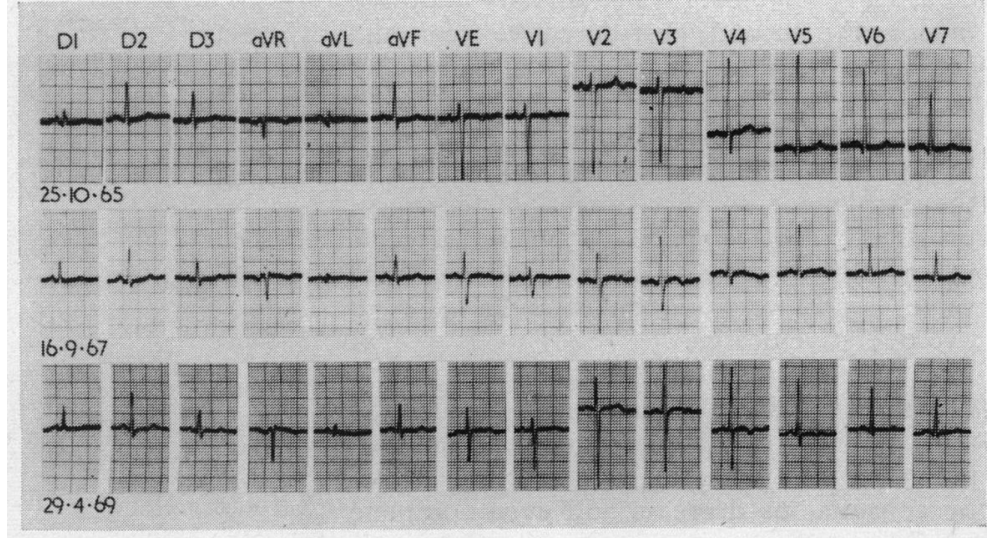


in 7 patients and was responsible to some extent for a rapidly deteriorating post-operative course. Of the 13 patients who had a poor functional result after annuloplasty, 9 had an intense tricuspid regurgitation (shown by phonocardiographic recordings in all the patients and by right heart catheterization in one). Of the 3 patients in whom a reconstructive procedure was attempted as a cure for tricuspid regurgitation, moderate tricuspid incompetence was still noted in 2 ; in the third case, $2 \frac{1}{2}$ years after operation there was a sudden increase in both mitral and tricuspid regurgitation. Whether or not tricuspid regurgitation was seen before operation, the pre-operative cardiothoracic ratios were not significantly different and averaged, respectively, $0.66 \pm 0.06$ and $0.60 \pm 0.04$. But all the patients but one who had tricuspid regurgitation were in atrial fibrillation before operation.

Relapse of rheumatic fever was not seen in this series, even in the youngest patients. In a 30-year-old woman, post-cardiotomy syndrome, with chest pains and electrocardiographic signs of pericarditis, was found and lasted 18 months but did not influence the functional improvement and was finally controlled by prolonged steroid therapy.

One patient, in spite of adequate surgical correction of mitral regurgitation, failed to improve and this might be explained by the presence of a myocardial factor: functional improvement remained moderate, and both radiological and electrocardiographic signs were unchanged. In this patient, before operation, the presence of blood polynuclear eosinophilia suggested fibroblastic endocarditis, which however was not found at operation.

Several pulmonary embolisms, which occurred more than 40 months after operation, in a man of 60 were partly responsible for rapid deterioration. However, gradually increasing cardiac failure had already appeared during the second post-operative year and coincided with the recurrence of mitral and tricuspid regurgitation.

A worsening clinical condition in 4 patients in a period ranging from the 37th month to the 48th made another operation necessary: prosthetic replacements of the mitral valve ( 3 cases) and of both mitral and tricuspid valve ( $I$ case) were undertaken and resulted in two operative deaths.

Over-all results Early after operation most patients benefited from mitral annuloplasty (Fig. I). This improvement was shown by conspicuous decrease and even complete

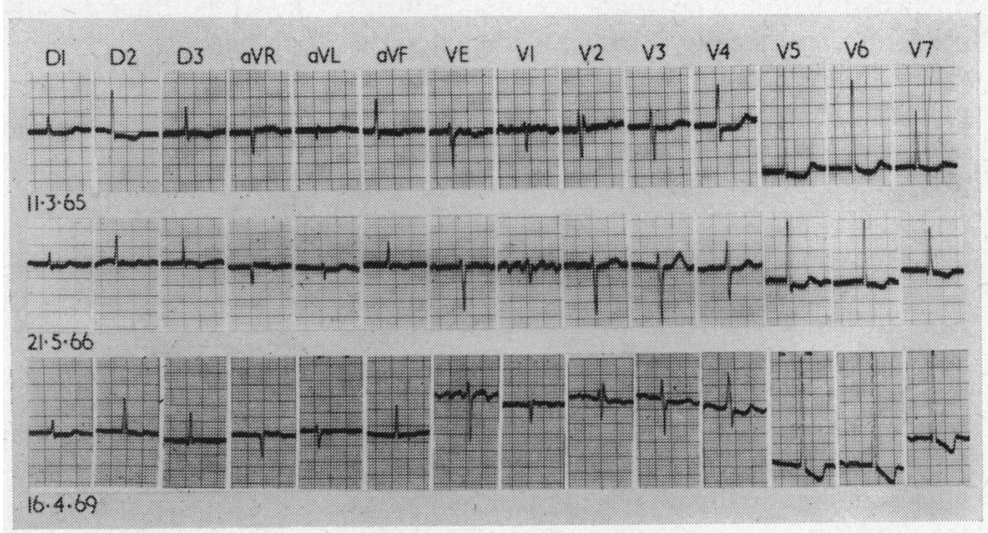

FIG. 6 Electrocardiographic changes in the same patient as in Fig. 4 (middle). Longstanding atrial fibrillation; note the reduction of $Q R S$ voltages and the disappearance of incomplete right ventricular bundle-branch block pattern within the 2 years after operation, and the return to the pre-operative pattern 44 months after annuloplasty (performed on 4 fune 1965).

disappearance of symptoms and was also confirmed by radiological and electrocardiographic data. As a consequence, within two years of operation more than two-thirds of the patients were able to carry out their ordinary activities. This improvement, however, could only be achieved when the patients were treated by digitalis and/or diuretics, and put on a reasonable salt-free diet.

Failure to maintain the fairly good results after operation, in spite of intense digitalis and/or diuretics treatment, was probably

FIG. 7 Same patient as in Fig. 4 (bottom); electrocardiogram changed little, if at all, 20 months and 45 months after annuloplasty (performed 15 October 1964).

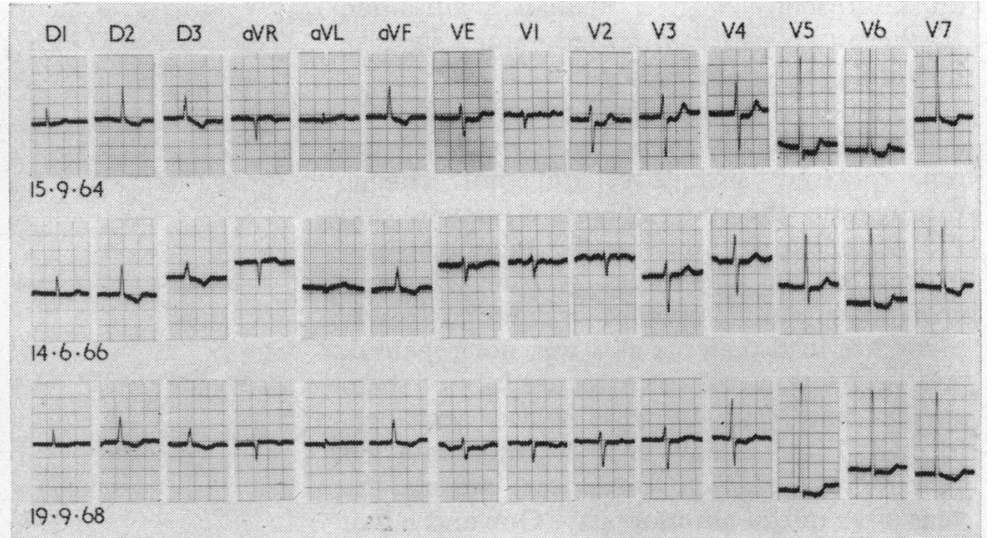


- no T.l.

O T.I. mild or moderate

O T.l.important

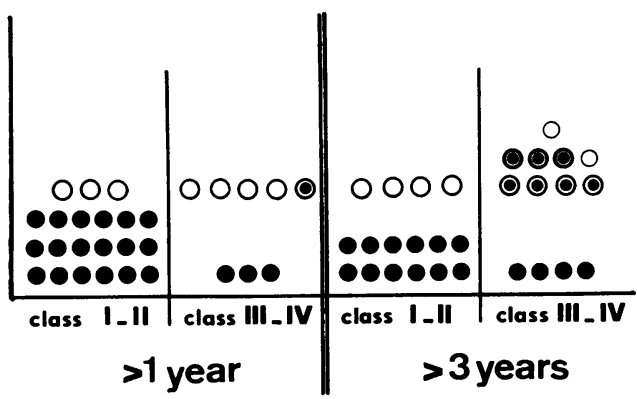

FIG. 8 Incidence of tricuspid insufficiency

(T.I.) and functional status more than I year

(left) and more than 3 years after operation

(right).

related to the fact that residual mitral insufficiency was still present after surgical repair and even gradually increased in 50 per cent of the patients, combined in some with the occurrence of tricuspid regurgitation.

Four years after operation, functional improvement was maintained in about 50 per cent of the operated patients, and they were able to carry out their ordinary activities without discomfort; one-third of them only were able to resume their professional activity. The long-term results were proportionally better and more durable in young patients with a short pre-operative period of cardiac failure, with a small heart size, and normal sinus rhythm.

\section{Discussion}

This follow-up study, lasting for more than three years after operation, showed that annuloplasty resulted in excellent to good results during the first two years after operation, and that this improvement was only partially maintained later on. These conclusions are in good agreement with those of Björk and Malers (1964), Ellis et al. (1965), and Aldridge, Lipton, and Bigelow (1966).

Favourable factors The good long-term results were more frequently observed in the youngest patients of this series: of the 7 patients aged less than 30 years, 5 were still in functional class I or II as against II of the 22 patients aged more than 30 years. The duration of the period of pre-operative congestive heart failure played a role, since the I6 operated patients whose improvement was maintained had been in congestive heart failure for less than 2 years on average; in 13 of them the congestive heart failure dated back less than I year. Of the 13 patients with more or less rapid post-operative deterioration, I I had been in congestive cardiac failure for more than 3 years. Pre-operative heart size was a determinant factor as well: 6 of the 7 patients who had a pre-operative cardiothoracic ratio less than 0.60 maintained their improvement. Furthermore, a good longterm result was usually noted when an important and rapid diminution of the cardiac size occurred after operation, and when the sinus rhythm was maintained or restored ( 9 of the ro patients in normal sinus rhythm).

The above factors were noted in the youngest patients and might explain to a large extent the lasting improvement seen in this group of subjects.

Adverse factors Diseased mitral leaflets left in situ seemed to invite subsequent deterioration, and this was so in half the operated patients.

The progression towards significant mitral stenosis was noted in only 2 of the 29 patients of this series, whereas Aldridge et al. (I966) observed it in 2 of their 9 patients. According to these authors, the development of mitral stenosis was more frequent in mixed valve lesions, i.e. combined mitral stenosis and insufficiency, and might be related to a continuing subclinical inflammatory process.

Recurrence and/or increase of a residual mitral insufficiency was responsible for most of the subsequent deteriorations. Incidence of residual mitral insufficiency has been differently estimated. After surgical repair of mitral insufficiency from ruptured chordae tendineae of the posterior leaflet the systolic murmur was abolished in most patients (Gerbode et al., 1968). But in 7 of the 8 patients of Logan, Turner, and Kitchin (1967) a systolic murmur was still audible 3 years after operation. Aldridge et al. (1966) demonstrated mitral regurgitation (4 of severe intensity and 2 of moderate degree) by haemodynamic and/or necropsy data in 6 of their 9 operated patients.

Residual mitral insufficiency was almost always present in this series, though, at the end of operation, the mitral valve was judged to be competent in all but 2 patients. In the early post-operative period, mild mitral regurgitation was suggested in most cases by the recurrence or the persistence of an apical systolic murmur, and in over half the cases by left atrial systolic expansion which could be seen fluoroscopically very soon after operation. With the passage of time, both the 
incidence and intensity of residual mitral insufficiency increased: I6 months after operation, I5 patients had obvious mitral regurgitation; 3 years after operation, conspicuous mitral regurgitation was noted in 19 patients, which was severe in 13. In the fourth year a prosthetic valve replacement was required in 4 patients. The recurrence of mitral insufficiency was more frequently seen when both a conspicuous cardiac enlargement and an atrial fibrillation were still present after operation. The degree of the mitral regurgitation was estimated on the clinical, radiological, and electrocardiographic data (rightward shift of the frontal major QRS axis, persistence or recurrence of left and/or right ventricular hypertrophy) and on the phonocardiographic recordings. As already emphasized by Logan et al. (1967), the apical systolic murmur loudness did not in this series bear a close relation to the importance of the regurgitant flow. As was shown in 4 patients at the time of re-operation and confirmed by necropsy in 2 of them, the occurrence of mitral regurgitation was not due to loosening of the sutures of annuloplasty but to dilatation of the portion of mitral annulus on which the posterior leaflet was inserted. Recurrence of mitral regurgitation might be explained by the fact that the first annuloplasties performed resulted in a moderately narrow mitral ring which was nevertheless enough to attain immediate competence. As a consequence, recurrence of even mild regurgitation results in circumstances that will allow the regurgitant flow to increase, thus leading to a vicious circle aggravating the disease.

Such an unfavourable course seemed to be inescapable whenever the surgical repair was not anatomically complete (Reed, Tice, and Clauss, I965; Hessel, Kennedy, and Merendino, 1966). The operative technique of annuloplasty involves two hazards: either persistence of regurgitation if the annuloplasty is too loose, or development of stenosis if the annuloplasty is too tight. Björk and Malers (1964) and Hessel et al. (1966) stated that annuloplasty should be abandoned in every case in which mitral insufficiency could not be corrected without narrowing the mitral ring (Reed et al., 1965; Reed, 1968) in order to avoid both risks calculated from Gorlin's hydraulic formula the mitral orifice area which should be attained by operation. A satisfactory solution was suggested and has been used for the past few months by Carpentier (1969) whenever the optimal anatomical features for annuloplasty were present. A competent annuloplasty without stenosis coutld be achieved by metallic wiring of the mitral ring, which will prevent its subsequent dilatation.

Most of the poor long-term results were related to the presence and severity of tricuspid incompetence, itself the commoner and the more severe the greater the pre-operative cardiac enlargement. All the patients with tricuspid insufficiency, except one, had atrial fibrillation. Severe tricuspid regurgitation was always found when a massive or developing post-operative mitral insufficiency was present: this was seen in 7 patients. Necropsy showed that mitral annuloplasty changed neither the morphology nor the function of the tricuspid valve, in spite of their close anatomical relation, and, therefore, mitral annuloplasty itself played no part in subsequent tricuspid valve dysfunction. The surgical treatment of tricuspid incompetence has not yet gained universal agreement. Some authors are inclined to disregard this lesion, when encountered in the course of open heart correction of mitral valve disease (Braunwald, Ross, and Morrow, 1967; Litwak et al., 1969). Others who try to correct the tricuspid regurgitation disagree on the type of operation to be performed, i.e. annuloplasty (Kay, Maselli-Campagna, and Tsuji, 1965) or valve replacement (Starr, Herr, and Wood, 1966). Grondin et al. (1967) and Himbert, Penther, and Lenègre (1967) recommended surgical correction of tricuspid regurgitation whenever it was severe.

The results of mitral annuloplasty were differently assessed. Logan et al. (1967) and Chapelle et al. (1969) considered that annuloplasty was the best method and must be used whenever the mitral valve lesions allowed for it. But, according to Effler (1962), the risk of recurrent mitral regurgitation entailed by this procedure was a good enough reason for not using it.

In the present study, though annuloplasty has been applied in selected cases of mitral insufficiency (after elimination of intensely sclerosed or calcified leaflets), it has the major disadvantage that lasting benefits are unpredictable even when the immediate result is a competent mitral valve.

Despite some advantages, it appears that annuloplasty alone has a limited place in the surgical repair of isolated mitral insufficiency, and that it should be recommended at best in 20 to 25 per cent of the cases of mitral insufficiency. Annuloplasty may be reasonably advised when the following conditions are met: mitral insufficiency with dilated mitral ring and slightly altered leaflets, moderate cardiac enlargement, normal sinus rhythm or short- 
standing atrial fibrillation, early congestive cardiac failure, and absence of any tricuspid insufficiency. Furthermore, mitral regurgitation resulting from ruptured chordae tendineae of the anterior leaflet must be deliberately excluded (Gerbode et al., 1968). A final assessment of the value of mitral annuloplasty cannot be made until a longer postoperative follow-up study is available in a group of patients selected as mentioned above. Indeed, it appears that some of the poor surgical results of mitral annuloplasty may be related to wide indications for operation.

The patients reviewed in this study were operated on by Dr. C. Dubost and his operative team (Dr. P. Blondeau and Dr. C. D'Allaines), by Dr. P. Daumet and by Dr. C. Cabrol. The authors thank Mrs. M. Desseigne and Miss E. Debray for their technical assistance.

\section{References}

Aldridge, H. E., Lipton, I. H., and Bigelow, W. G. (1966). Annuloplasty for mitral insufficiency. A five to six-year clinical and hemodynamic followup. Circulation, 34, 337.

Björk, V. O., and Malers, E. (1964). Annuloplastic procedures for mitral insufficiency: late results. Fournal of Thoracic and Cardiovascular Surgery, 48, $25 \mathrm{I}$.

Blondeau, M., Maurice, P., and Lenègre, J. (1962). L'électrocardiogramme de la communication interauriculaire. Archives des Maladies du Coeur et des Vaisseaux, 55, 1004 .

Braunwald, N. S., Ross, J., Jr., and Morrow, A. G. (1967). Conservative management of tricuspid regurgitation in patients undergoing mitral valve replacement. Circulation, 35-36, Suppl. I, 63.

Carpentier, A. (1969). La valvuloplastie reconstitutive. Une nouvelle technique de valvuloplastie mitrale. Presse Médicale, 77, 251.

Chapelle, M., Cabrol, C., Guiraudon, G., Luciani, G., Cappe, M. C., Berges, J., and Marouani, A. (I969). Résultats éloignés et comparatifs dans le traitement de l'insuffisance mitrale par l'annuloplastie ou le remplacement valvulaire par la prothèse de Starr. Archives des Maladies du Coeur et des Vaisseaux, 62, 289 (Résumé).

Effler, D. B. (1962). Defects of the mitral valve: cur- rent concepts of surgical treatment. Cleveland Clinic Quarterly, 29, 167.

Ellis, F. H., Jr., Callahan, J. A., McGoon, D. C., and Kirklin, J. W. (1965). Results of open operation for acquired mitral-valve disease. New England Fournal of Medicine, 272, 869.

Gerbode, F., Hill, J. D., Kelly, J. J., Jr., Selzer, A., and Kerth, W. J. (I968). Surgical correction of mitral insufficiency due to ruptured chordae tendineae. Circulation, 37-38, Suppl. 2, I19.

Grondin, P., Lepage, G., Castonguay, Y., and Meere, C. (1967). The tricuspid valve: a surgical challenge. fournal of Thoracic and Cardiovascular Surgery, 53, 7.

Hessel, E. A., III, Kennedy, J. W., and Merendino, K. A. (1966). A reappraisal of nonprosthetic reconstructive surgery for mitral regurgitation based on an analysis of early and late results. fournal of Thoracic and Cardiovascular Surgery, 52, 193.

Himbert, J., Penther, P., and Lenègre, J. (1967). La correction de l'insuffisance tricuspidienne dans la chirurgie à coeur ouvert des cardiopathies mitrales et mitro-aortiques. Archives des Maladies du Coeur et des Vaisseaux, 60, 1460

Kay, J. H., Maselli-Campagna, E., and Tsuji, H. K. (1965). Surgical treatment of tricuspid insufficiency. Annals of Surgery, 162, 53.

Litwak, R. S., Silvay, J., Gadboys, H. L., Lukban, S. B., Sakurai, H., and Castro-Blanco, J. (1969). Factors associated with operative risk in mitral valve replacement. American fournal of Cardio$\log y, 23,335$.

Logan, A., Turner, R. W. D., and Kitchin, A. H. (1967). Surgical treatment of mitral incompetence. British Heart fournal, 29, I.

Penther, P., Maurice, P., Ben Ismail, M., Bourdarias, J. P., and Lenègre, J. (1966). Les myocardopathies obstructives. II. Étude électrocardiographique: à propos de 50 cas. Archives des Maladies du Coeur et des Vaisseaux, 59, 712.

Reed, G. E. (1968). Surgical treatment of valvular heart disease. IV. Mitral valve surgery. American Heart Fournal, 76, 432 .

- Tice, D. A., and lauss, R. H. (1965). Asymmetric exaggerated mitral annuloplasty: repair of mitral insufficiency with haemodynamic predictability. Fournal of Thoracic and Cardiovascular Surgery, 49, 752.

Starr, A., Herr, R., and Wood, J. (I966). Tricuspid replacement for acquired valve disease. Surgery, Gynecology and Obstetrics, 122, 1295.

Wooler, G. H., Nixon, P. G. F., Grimshaw, V. A., and Watson, D. A. (1962). Experiences with the repair of the mitral valve in mitral incompetence. Thorax, 17, 49. 